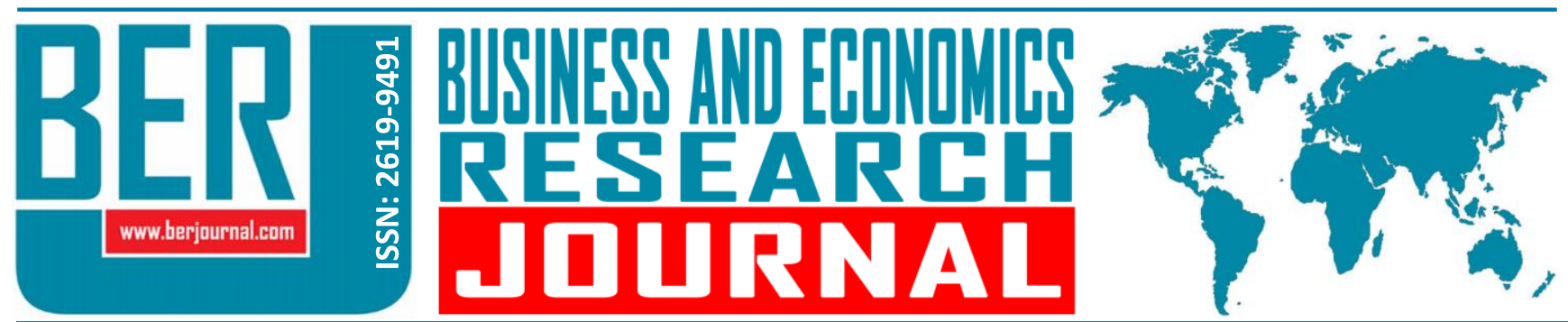

Business and Economics Research Journal Vol. 9, No. 3, 2018, pp. 499-512 doi: 10.20409/berj.2018.119

\title{
Ana Sektörlerin Enerji Tüketimlerinin Ekonomik Büyüme Üzerine Etkisi: Türkiye Örneği (1972-2015)
}

\author{
Tuba Hanifi ${ }^{\mathrm{a}}$, Aysun Eser Ozen ${ }^{\mathrm{b}}$
}

Öz: Bu çalışmanın amacı, 1972-2015 yılları arasında Türkiye'de enerji tüketiminin ekonomik büyüme üzerine etkisinin ana sektörler bazında analiz edilmesidir. Çalışmada ilk önce değişkenler arasındaki bağımlılık ilişkisi Yatay Kesit Bağımlılığı (CD test) yöntemiyle test edilmiş, daha sonra enerji tüketimi ve Gayrisafi Yurtiçi Hâsıla arasındaki nedensellik ilişkisi Dumitrescu ve Hurlin tarafından geliştirilen heterojen panel testiyle analiz edilmiştir. Buna göre Türkiye'de büyümeden enerji tüketimine doğru tek yönlü bir nedensellik ilişkisi bulunmuştur. Ana sektörler açısından ise, tarım sektöründe büyümeden enerji tüketimine doğru tek yönlü, hizmetler sektöründe büyüme ve enerji tüketimi arasında çift yönlü nedensellik ilişkisi bulunmuştur. Sanayi sektörü açısından ise herhangi bir nedensellik bağı bulunamamıştır.

\section{Effects of Sectoral Energy Consumption on Economic Growth: The Case of Turkey (1972-2015)}

\begin{abstract}
The aim of this study is to analyse the impact of energy consumption on economic growth in the basis of main sectors, between the years 1972-2015 in Turkey. The dependency between variables was tested by the method of Horizontal Cross Section (CD test), then the causality between energy consumption and Gross Domestic Product was analysed by using the heterogeneous panel test developed by Dumitrescu and Hurlin. Unidirectional causality from growth to energy consumption was found for Turkey. In terms of the main sectors, unidirectional causality from growth to energy consumption in the agricultural sector and bi-directional causality between growth and energy consumption in the services sector was found. In terms of the industrial sector, no causality was found.
\end{abstract}

\author{
Anahtar Sözcükler: Enerji \\ tüketimi, Ekonomik Büyüme, \\ Sektörler, Nedensellik, \\ Türkiye \\ JEL: C33, Q43, E23, 049 \\ Gelis : 13 Nisan 2018 \\ Düzeltme : 24 Mayıs 2018 \\ Kabul : 27 Haziran 2018 \\ Tür : : Araştırma
}

Keywords: Energy Consumption, Economic Growth, Sectors, Causality, Turkey

JEL: C33, Q43, E23, O49

$\begin{array}{ll}\text { Received } & : 13 \text { April } 2018 \\ \text { Revised } & : 24 \text { May } 2018 \\ \text { Accepted } & : 27 \text { June } 2018 \\ & \\ \text { Type } & : \text { Research }\end{array}$

Type : Research

a PhD. Student, Nevsehir Hacıbektas Veli University, Social Sciences Institute, Nevsehir, Turkiye, tubahanifi@hotmail.com (ORCID ID: 0000-0002-7642-3769)

b Asst. Prof., PhD., Nevsehir Hacıbektas Veli University, Faculty of Economics and Administrative Sciences, Nevsehir, Turkiye, aysun@nevsehir.edu.tr (ORCID ID: 0000-0003-3253-056X)

* Bu çalışma, Nevşehir Hacı Bektaş Veli Üniversitesi Sosyal Bilimler Enstitüsü İktisat Anabilim Dalı yüksek lisans öğrencisi Tuba Hanifi tarafından Dr. Öğr. Üyesi Aysun Eser Özen danışmanlığında tamamlanan “Ana Sektörlerin Enerji Tüketimlerinin Ekonomik Büyüme Üzerine Etkisi: Türkiye Örneği (1972-2015)" adlı yüksek lisans tezinden türetilmiştir. 


\section{Giriş}

Enerji tüketimi ve ekonomik büyüme arasındaki ilişkinin önemi 1970'lerde yaşanan Petrol Krizleri ile ortaya çıkmış, artan petrol fiyatlarının ülke ekonomilerini kötü etkilemesiyle birçok araştırmaya konu oluşturmuştur. Üretim ve tüketim faaliyetlerinde enerjinin girdi olarak kullanılması, enerjinin ekonomik büyüme üzerindeki etkisinin önemli olup olmadığı sorusunu gündeme getirmiştir (Çetin ve Şeker, 2012: 86). Böylece 1970'lerin petrol şoklarından bu yana, enerji verimliliği tüm ülkeler için büyük bir endişe kaynağı olmuş ve enerji tüketimi ile büyüme arasındaki ilişkinin incelenmesine yönelik ilgi artmıştır (Hammami ve Saidi 2015: 270). Bu doğrultuda, enerji tüketimi ve büyüme arasındaki ilişkiyi inceleyen çalışmalar günümüzde de hızla artmaktadır.

Türkiye'de enerji tüketimi, sanayileşme ve nüfus artışına bağlı olarak 1980'lerin sonlarına doğru hızla artış göstermiştir. Bunun temel nedeni tarımın nispi öneminin azalması, sanayi ve hizmetler sektörünün ön plana çıkmasıdır. Türkiye' de ekonominin genel yapısında ortaya çıkan bu değişim, daha fazla enerji tüketimine neden olmuş böylece petrol, kömür ve doğal gaz gibi fosil yakıtlara talep artmıştır (Mucuk ve Uysal, 2009: 106). Türkiye'de, dışa bağımlıı̆ın en fazla olduğu sektörlerin başında enerji sektörü gelmektedir. Enerji tüketiminde Türkiye'nin dışa bağımlı olması cari açığı etkilemekle birlikte ekonomik büyümeye de yansımaktadır. Enerji ithalatına olan bağımlılık cari açığı artırmakta, girdi maliyetleri artmakta sonuçta artan fiyatlara bağı olarak ülkenin rekabet gücü olumsuz etkilenmektedir (Korkmaz ve Develi, 2012: 4-5). Sonuçta ekonomik büyüme de olumsuz etkilenebilmektedir, enerji tüketimi ve ekonomik büyüme ilişkisinin incelenmesi de önem arz etmektedir.

Türkiye'de söz konusu ilişkiyi inceleyen çok sayıda çalışma bulunmasına rağmen, sektörel ayrıma göre yapılan çalışmaların sayısı oldukça kısıtıdır. Bu çalışmanın diğer çalışmalardan başlıca farkı, söz konusu ilişkinin ana sektörler ayrımı yapılarak incelenmesidir. Çalışmanın amacı, Türkiye'de ana sektörlere ait toplam enerji tüketimi ile ekonomik büyüme arasında ilişki olup olmadığının ve ilişkinin yönünün incelenmesidir. Analiz dönemi, değişkenlere ait verilerin elde edilebilirliğinden dolayı 1972-2015 yıl aralı̆̆ı ile kısıtlanmıştır. Çalışmada ilk olarak Pesaran (2004) tarafından geliştirilen "CD (Cross-Sectional Dependence) Testi" kullanılarak sektörler arası yatay kesit bağımlıı̆ı̆ araştırılmıştır. Daha sonra serilerin durağanlık analizi için Im, Pesaran, Shin (2003) tarafından geliştirilen IPS testi ile Pesaran (2007) tarafından geliştirilen CIPS (Crosssectionally Augmented IPS) testi kullanılmıştır. Son olarak, değişkenler arasındaki nedenselliğin yönünü belirlemek için Dumitrescu ve Hurlin (2012) tarafından geliştirilen heterojen panel nedensellik testi uygulanmıştır.

Çalışma beş bölümden oluşmaktadır. Giriş bölümünün ardından ikinci bölümde enerji tüketimi ve büyüme arasındaki ilişki için yapılan çalışmalara ait literatür taramasına yer verilmiş, literatürdeki çalışmalar tablo halinde özetlenmiştir. Üçüncü bölümde Türkiye'de ana sektörlerin enerji tüketimlerinin GSYH ile ilişkisinden bahsedilmiştir. Dördüncü bölümde metodoloji ve veriler hakkında bilgi verilerek, analizlerden elde edilen sonuçlar değerlendirilmiştir. Son bölümde ise sonuç ve politika önerileri ortaya konulmuştur.

\section{Literatür Taraması}

Enerji ile ekonomik büyüme ilişkisi, daha yüksek ekonomik büyümenin daha fazla enerji tüketimi gerektirdiği ve daha verimli bir enerji kullanımının daha yüksek düzeyde bir ekonomik büyümeye ihtiyaç duyduğu sonucunu ortaya koymaktadır. Yapılan çalışmalarda kullanılan yöntemlerin, değişkenlerin, zaman aralığının, seçilen ülkelerin farklı olması nedeniyle elde edilen sonuçlar da farklılık göstermektedir. Ayrıca yenilenebilen ya da yenilenemeyen enerji kaynakları, elektrik tüketimi gibi çeşitli enerji kaynaklarının tüketimi ile ilgili konularda da çalışmalar yapılmaktadır. Bu çalışmalardan büyüme üzerine elde edilen olumlu sonuçlar ekonomi için çeşitli politika çıkarımları yapılmasını sağlamaktadır.

Enerji tüketimi ve ekonomik büyüme arasındaki ilişkiyi makro düzeyde ve mikro düzeyde (sektörel olarak) araştıran çalışmaların bulguları arasında farklılıklar söz konusudur. Bu ilişkiyi makro düzeyde inceleyen çalışmalar, nedenselliğin yönüne göre enerji tüketimi ve ekonomik büyüme arasında çift yönlü ilişki olduğu sonucuna ulaşan (enerji kaynaklı büyüme hipotezi, büyüme kaynaklı enerji hipotezi) ve aralarında herhangi bir ilişkinin olmadığı sonucuna ulaşan (yansızlık hipotezi) çalışmalardır. Günümüzde enerji tüketimi ve 
ekonomik büyüme arasındaki ilişkiyi nedensellik ilişkisinin yönünü de dikkate alarak inceleyen birçok çalışma yapılmaktadır. Yapılan çalışmalarda nedenselliğin yönü açısından dört durum söz konusudur (Apergis ve Payne, 2009: 642-643; Öztürk, 2010: 340-341).

1.Enerjiden büyümeye doğru tek yönlü nedensellik: Buna "büyüme hipotezi" de denilmektedir. Büyüme hipotezi enerji tüketiminin hem üretim sürecinde doğrudan girdi olarak hem de dolaylı olarak, emek ve sermaye girdilerini tamamlayıcı nitelikte, ekonomik büyüme üzerinde etkili olduğunu göstermektedir. Enerji tüketiminin azaltılması ekonomik büyümeyi olumsuz etkilemekte, enerji tüketimi artışı ise ekonomik büyümeye katkıda bulunmaktadır. Buna bağıı olarak, enerji arzında yaşanan şoklar ekonomik büyümeyi olumsuz yönde etkilemektedir.

2. Büyümeden enerjiye doğru tek yönlü nedensellik: Buna "koruma hipotezi" de denilmektedir. Ekonomik büyümede yaşanan bir gelişme enerji tüketimini etkilemektedir. Örneğin reel GSYH'de ortaya çıkan bir artış, enerji tüketimi üzerinde bir artış yaratıyorsa burada koruma hipotezinin desteklendiği varsayılmaktadır.

3. Çift yönlü nedensellik: "Geri besleme hipotezi" de denilmektedir. Enerji tüketimi ekonomik büyümeyi, ekonomik büyüme de enerji tüketimini etkilemektedir. Yani çift yönlü nedensellik söz konusudur.

4. Nedenselliğin olmaması: Enerji tüketimi ile büyüme arasında nedensellik olmaması "tarafsızlık hipotezi" olarak adlandırılmakta olup, bu hipotez enerji tüketimi ile Gayrisafi Yurtiçi Hâsıla (GSYH) arasında ilişki bulunmadığını göstermektedir.

Ekonomik büyüme ve enerji arasındaki ilişkiyi Granger nedensellik testi yaklaşımı ile ilk inceleyen Kraft ve Kraft'ın (1978) çalışması, diğer araştırmacılar için öncü çalışma haline gelmiştir. 1947-1974 dönemlerinde Sim's tekniği kullanılarak Amerika'daki enerji tüketimi ve büyüme arasındaki nedensellik ilişkisini inceleyen çalışmada, büyümeden enerji tüketimine doğru tek yönlü nedensellik olduğu sonucuna ulaşılmıştır. Bu çalışmayı takiben, farklı ülkelerde bu ilişkiyi inceleyen çalışmaların sayısı hızla artmıştır. Yu ve Hwang'ın (1984), 1947-1949 dönemi Amerika verilerini ve Sim's tekniğini kullanarak yaptıkları çalışmada, enerji tüketimi ve GSYH arasında herhangi bir ilişkiye rastlanılmamıştır. Yu ve Choi'nin (1985) çalışmalarında, enerji ve gayri safi milli hasıla (GSMH) arasındaki ilişkinin ve nedensellik sonuçlarının seçilen beş ülkeye göre değiştiği ifade edilmiştir. Altınay ve Karagöl (2004), 1950-2000 döneminde Türkiye'de elektrik tüketimi ile reel GSYH arasındaki nedensel ilişkiyi araştırmışlardır. Çalışmada elektrik tüketiminden GSYH'ya doğru tek yönlü nedensellik olduğu sonucuna ulaşmışlardır. Lee (2005), 18 gelişmekte olan ülkenin 1975-2004 verilerini kullanarak enerji tüketimi ve GSYH arsındaki ilişkiyi incelemiş, kısa ve uzun dönemde enerji tüketiminden GSYH'ye doğru bir nedensellik ilişkisi bulmuştur. Chen vd. (2007), 10 Asya ülkesinde elektrik tüketimi ve GSYH arasındaki ilişkiyi incelemek için, 1971-2001 dönemlerini içeren bir analiz yapmışlardır. Buna göre kısa dönemde elektrik tüketiminden ekonomik büyümeye doğru tek yönlü nedensellik olduğu tespit edilmiştir. Narayan ve Smyth (2008), yaptıkları Granger nedensellik analizinden hareketle, G7 ülkelerinde sermaye oluşumu ve enerji tüketiminin uzun dönemde reel GSYH'yı olumlu etkilediği sonucuna ulaşmışlardır. Belloumi (2009), 1971-2004 döneminde kişi başı enerji tüketimi ve kişi başına düşen GSYH arasındaki nedensel ilişkiyi incelemiş, iki değişken arasında uzun dönemde çift yönlü, kısa dönemde ise kişi başı GSYH'den kişi başı enerji tüketimine doğru tek yönlü bir nedensellik bulmuştur. 2010 yılı ve sonrasında konu ile ilgili olarak yapılan başlıca çalışmalar Tablo 1'de özetlenmiştir.

Literatürde az sayıda da olsa, enerji tüketimi ve ekonomik büyüme arasındaki ilişkiyi ana sektörler bazında (tarım, sanayi ve hizmet olarak) inceleyen çalışmalar da bulunmaktadır. Bu çalışmalar Tablo 2'de görülmektedir.

Literatürde enerji tüketimi ve ekonomik büyümeyi makro ve mikro olarak inceleyen birçok çalışma yer almakla birlikte, bu çalışmada hepsine yer verilememiştir. Bu nedenle ilgili göstergelere ait son dönemde yapılan çalışmalara ait sonuçlar Tablo1 ve Tablo 2'de gösterilmiştir. 
Ana Sektörlerin Enerji Tüketimlerinin Ekonomik Büyüme Üzerine Etkisi: Türkiye Örneği (1972-2015)

Tablo 1. Enerji Tüketimi ve Ekonomik Büyüme Literatür Özeti (2010 Sonrası)

\begin{tabular}{|c|c|c|c|c|}
\hline Yazar & $\begin{array}{l}\text { Zaman } \\
\text { Aralığı }\end{array}$ & Ülke Grubu & $\begin{array}{l}\text { Ekonometrik } \\
\text { Yöntem }\end{array}$ & Sonuç \\
\hline $\begin{array}{l}\text { Jamil ve Ahmad } \\
\text { (2010) }\end{array}$ & $1960-2008$ & Pakistan & $\begin{array}{l}\text { Granger nedensellik } \\
\text { testi, Johansen } \\
\text { Eşbütünleşme testi }\end{array}$ & $\mathrm{G} \rightarrow \mathrm{E}$ \\
\hline $\begin{array}{l}\text { Shuyun ve Donghu } \\
\text { (2011) }\end{array}$ & $1985-2007$ & Çin & $\begin{array}{l}\text { Granger nedensellik } \\
\text { testi }\end{array}$ & $E \leftrightarrow G$ \\
\hline Shahbaz vd. (2011) & 1971-2009 & Portekiz & $\begin{array}{l}\text { Johansen-Juselius } \\
\text { Eşbütünleşme testi, } \\
\text { Granger nedensellik } \\
\text { testi }\end{array}$ & $\mathrm{E} \leftrightarrow \mathrm{G}$ \\
\hline $\begin{array}{l}\text { Apergis ve Payne } \\
\text { (2012) }\end{array}$ & $1990-2007$ & 80 ülke & $\begin{array}{l}\text { Pedroni heterojen } \\
\text { Panel Eşbütünleşme } \\
\text { testi, } \\
\text { Granger nedensellik } \\
\text { testi }\end{array}$ & $\begin{array}{l}\text { Yenilenebilir enerji tüketimi } \leftrightarrow \\
\text { Ekonomik büyüme }\end{array}$ \\
\hline Al- Mulali vd. (2013) & $1980-2009$ & $\begin{array}{l}\text { Yüksek gelir, üst orta } \\
\text { gelir, alt orta gelir ve } \\
\text { yüksek gelirli ülkeler }\end{array}$ & $\begin{array}{l}\text { Tamamen } \\
\text { değiştirilmiş OLS } \\
\text { (FMOLS) tahminleri }\end{array}$ & $\begin{array}{l}108 \text { ülke arasından } 85 \text { ülkede: } \\
\text { Yenilenebilir enerji tüketimi } \leftrightarrow \\
\text { Ekonomik büyüme }\end{array}$ \\
\hline Uçan vd. (2014) & $1990-2011$ & 15 Avrupa ülkesi & $\begin{array}{l}\text { Pedroni Panel } \\
\text { Eşbütünleşme testi, } \\
\text { Tamamen } \\
\text { değiştirilmiş OLS } \\
\text { (FMOLS) yöntemi, } \\
\text { Granger nedensellik } \\
\text { testi }\end{array}$ & $E \rightarrow G$ \\
\hline $\begin{array}{l}\text { Hammami ve Saidi } \\
\text { (2015) }\end{array}$ & $1974-2011$ & Tunus & $\begin{array}{l}\text { Granger nedensellik } \\
\text { testi, } \\
\text { Johansen } \\
\text { Eşbütünleşme testi }\end{array}$ & $\mathrm{E} \leftrightarrow \mathrm{G}$ \\
\hline $\begin{array}{l}\text { Bildirici ve Ersin } \\
\text { (2015) }\end{array}$ & $1970-2013$ & $\begin{array}{l}\text { Avusturya, Kanada, } \\
\text { Almanya, İngiltere, } \\
\text { Finlandiya, Fransa, } \\
\text { İtalya, } \\
\text { Meksika, Portekiz, } \\
\text { ABD }\end{array}$ & $\begin{array}{l}\text { Otoregresif } \\
\text { dağıtılmış gecikme } \\
\text { (ARDL) testi, } \\
\text { Granger nedensellik } \\
\text { testi, } \\
\text { Toda-Yamamoto } \\
\text { nedensellik testi } \\
\end{array}$ & $\begin{array}{l}\text { Avusturya, Almanya, Finlandiya, } \\
\text { Portekiz: } G \rightarrow E \\
\text { ABD: } E \leftrightarrow G\end{array}$ \\
\hline Mutascu (2016) & $1970-2012$ & G7 Ülkeleri & $\begin{array}{l}\text { Granger nedensellik } \\
\text { testi }\end{array}$ & $\begin{array}{l}\text { Kanada, Japonya, ABD: } \mathrm{E} \leftrightarrow \mathrm{G} \\
\text { Fransa, Almanya: } \mathrm{G} \rightarrow \mathrm{E} \\
\text { İtalya, Birleşik Krallık: } \varnothing\end{array}$ \\
\hline Aslan ve Öcal (2016) & 1990-2009 & $\begin{array}{l}\text { AB'ye yeni üye olan } \\
\text { ülkeler (Bulgaristan, } \\
\text { Kıbrıs, Çek Cumhuriyeti, } \\
\text { Estonya, Macaristan, } \\
\text { Polonya, Romanya ve } \\
\text { Slovenya) }\end{array}$ & $\begin{array}{l}\text { ARDL testi, } \\
\text { Asimetrik } \\
\text { nedensellik } \\
\text { yaklaşımı }\end{array}$ & $\begin{array}{l}\text { Seçilen tüm ülkelerde yenilenebilir } \\
\text { enerji tüketiminin ekonomik büyüme } \\
\text { üzerinde olumlu etkileri olduğuna } \\
\text { ulaşılmıştır. Ayrıca Çek Cumhuriyeti } \\
\text { için koruma hipotezi, Kıbrıs, Estonya, } \\
\text { Macaristan, Polonya ve Slovenya için } \\
\text { tarafsızlık hipotezinin varlığı } \\
\text { desteklenmiştir. }\end{array}$ \\
\hline Ito (2017) & $2002-2011$ & 42 Gelişmiş ülke & GMM & $E \rightarrow G$ \\
\hline $\begin{array}{l}\text { Destek ve Aslan } \\
\text { (2017) }\end{array}$ & $1980-2012$ & 17 Gelişmekte olan ülke & $\begin{array}{l}\text { Bootstrap panel } \\
\text { nedensellik testi }\end{array}$ & $\begin{array}{l}\text { Yenilenebilir enerji tüketimi } \\
\text { olduğunda; Peru: } \mathrm{E} \rightarrow \mathrm{G} \text { Kolombiya ve } \\
\text { Tayland: } \mathrm{G} \rightarrow \mathrm{E} \text { Yunanistan Güney } \\
\text { Kore: } \mathrm{E} \leftrightarrow \mathrm{G} \\
\text { Diğer } 12 \text { ülke: } \varnothing \\
\text { Yenilenebilir enerji tüketimi } \\
\text { bulunmadığında; Çin, Kolombiya, } \\
\text { Meksika ve Filipinler: } \mathrm{E} \rightarrow \mathrm{G} \\
\text { Mısır, Peru ve Portekiz: G } \rightarrow \mathrm{E} \\
\text { Türkiye: } \mathrm{E} \leftrightarrow \mathrm{G} \\
\text { Diğer } 9 \text { ülke: } \varnothing\end{array}$ \\
\hline
\end{tabular}




\begin{tabular}{|l|l|l|l|l|}
\hline $\begin{array}{l}\text { Bakırtaş ve Akpolat } \\
\text { (2018) }\end{array}$ & 1971-2014 & $\begin{array}{l}\text { Kolombiya, Endonezya, } \\
\text { Meksika, Hindistan, } \\
\text { Malezya, Kenya }\end{array}$ & $\begin{array}{l}\text { Dumitrescu-Hurlin } \\
\text { panel nedensellik } \\
\text { testi, } \\
\text { Carrion-i Silvestre } \\
\text { panel durağanlık } \\
\text { testi }\end{array}$ & $\begin{array}{l}\text { Meksika: } \mathrm{E} \rightarrow \mathrm{G} \\
\text { Diğer ülkelerde: } \mathrm{G} \rightarrow \mathrm{E}\end{array}$ \\
\hline $\begin{array}{l}\text { Tuğcu ve Topcu } \\
\text { (2018) }\end{array}$ & 1980-2014 & G7 ülkeleri & $\begin{array}{l}\text { Doğrusal olmayan } \\
\text { otoregresif } \\
\text { dağıtılmış gecikme } \\
\text { (NARDL) testi, } \\
\text { Asimetrik } \\
\text { nedensellik } \\
\text { yaklaşımları }\end{array}$ & $\begin{array}{l}\text { Uzun dönemde enerji tüketimi ve } \\
\text { ekonomik büyüme arasında asimetrik } \\
\text { bir ilişkinin varlığı desteklenmiştir. }\end{array}$ \\
\hline
\end{tabular}

Not: $\mathrm{E} \rightarrow \mathrm{G}$ enerjiden büyümeye doğru tek yönlü nedenselliği, $\mathrm{G} \rightarrow \mathrm{E}$ büyümeden enerjiye doğru tek yönlü nedenselliği, $\mathrm{E} \leftrightarrow \mathrm{G}$ çift yönlü nedenselliği, $\varnothing$ nedensellik ilişkisi olmadığını ifade etmektedir.

Tablo 2. Enerji Tüketimi ve Ekonomik Büyüme Iliş̧kisini Sektör Ayrımı Yaparak İnceleyen Çalışmalar

\begin{tabular}{|c|c|c|c|c|}
\hline Yazar & $\begin{array}{l}\text { Zaman } \\
\text { Aralığı }\end{array}$ & Ülke Grubu & Ekonometrik Yöntem & Sonuç \\
\hline Wolde-Rufael (2004) & 1952-1999 & Şanghay & Granger nedensellik testi & Sanayi sektörü: $E \rightarrow G$ \\
\hline Jumbe (2004) & 1970-1999 & Malavi & $\begin{array}{l}\text { Genişletilmiş Dickey-Fuller } \\
\text { birim kök testi (ADF) } \\
\text { Phillips-Perron birim kök testi } \\
\text { (PP) } \\
\text { Nedensellik testi } \\
\text { Hata Düzeltme Modeli }\end{array}$ & $\begin{array}{l}\text { GSYH } \leftrightarrow \text { Elektrik Tüketimi } \\
\text { Tarımsal GSYH } \rightarrow \text { Elektrik Tüketimi }\end{array}$ \\
\hline $\begin{array}{l}\text { Jobert ve Karanfil } \\
\text { (2007) }\end{array}$ & $1960-2003$ & Türkiye & $\begin{array}{l}\text { Johansen Eşbütünleşme testi } \\
\text { Granger nedensellik testi }\end{array}$ & Sanayi sektörü: $\varnothing$, \\
\hline $\begin{array}{l}\text { Bowden ve Payne } \\
\text { (2009) }\end{array}$ & 1949-2006 & $A B D$ & $\begin{array}{l}\text { Toda-Yamamoto nedensellik } \\
\text { testi }\end{array}$ & $\begin{array}{l}\text { Ulaştırma sektörü: } \varnothing \text {, } \\
\text { Ticaret ve konut sektörü: } E \leftrightarrow G \\
\text { Sanayi sektörü: } E \rightarrow G\end{array}$ \\
\hline Tsani (2010) & $1970-2006$ & Yunanistan & $\begin{array}{l}\text { Toda-Yamamoto nedensellik } \\
\text { testi }\end{array}$ & $\begin{array}{l}\text { Sanayi ve konut sektörü: } \mathrm{E} \leftrightarrow \mathrm{G} \text {, } \\
\text { Ulaştırma sektörü: } \varnothing\end{array}$ \\
\hline Gross (2012) & 1970-2007 & $A B D$ & $\begin{array}{l}\text { Panel ARDL } \\
\text { Granger nedensellik testi }\end{array}$ & $\begin{array}{l}\text { Ulaştırma sektörü: } G \leftrightarrow E \\
\text { Ticaret sektörü: } G \rightarrow E\end{array}$ \\
\hline $\begin{array}{l}\text { Hamit-Haggar } \\
\text { (2012) }\end{array}$ & 1990-2007 & Kanada & Granger nedensellik testi & Sanayi sektörü; G $\rightarrow E$ \\
\hline Sebri ve Abid (2012) & 1980-2007 & Tunus & $\begin{array}{l}\text { ADP ve PP birim kök testleri } \\
\text { Johansen Eşbütünleşme testi } \\
\text { Granger nedensellik testi }\end{array}$ & $\begin{array}{l}\text { Enerji tüketiminin tarım } \\
\text { sektöründe katma değere neden } \\
\text { olduğu sonucu elde edilmiştir. }\end{array}$ \\
\hline Zhang ve Xu (2012) & 1998-2008 & Çin & Granger nedensellik testi & Sanayi sektörü: $E \leftrightarrow G$ \\
\hline $\begin{array}{l}\text { Abbas ve Choudhury } \\
\text { (2013) }\end{array}$ & $1972-2008$ & $\begin{array}{l}\text { Pakistan ve } \\
\text { Hindistan }\end{array}$ & Granger nedensellik testi & $\begin{array}{l}\text { Hindistan'da tarımdaki elektrik } \\
\text { tüketimi } \leftrightarrow \text { GSYH, } \\
\text { Pakistan'da GSYH } \rightarrow \text { tarımdaki } \\
\text { elektrik tüketimi }\end{array}$ \\
\hline $\begin{array}{l}\text { Saunoris ve } \\
\text { Sheridan (2013) }\end{array}$ & 1970-2009 & $A B D$ & Granger nedensellik testi & $\begin{array}{l}\text { Sanayi sektörü; } E \rightarrow G \text { (kısa } \\
\text { dönem) } \\
\text { G } \rightarrow E \text { (uzun dönem) } \\
\text { Ticaret ve Konut sektörü; G } \rightarrow E\end{array}$ \\
\hline $\begin{array}{l}\text { Şahbaz ve Yanar } \\
\text { (2013) }\end{array}$ & $1970-2010$ & Türkiye & $\begin{array}{l}\text { Toda-Yamamoto nedensellik } \\
\text { testi }\end{array}$ & $\begin{array}{l}\mathrm{G} \rightarrow \mathrm{E} \\
\text { Ulaştırma-Tarım: } \mathrm{G} \rightarrow \mathrm{E} \\
\text { Sanayi-Konut: } \varnothing\end{array}$ \\
\hline $\begin{array}{l}\text { Tang ve Shahbaz } \\
\text { (2013) }\end{array}$ & $1972-2010$ & Pakistan & Granger nedensellik testi & $\begin{array}{l}\text { Sanayi ve hizmet sektörü; } \mathrm{E} \rightarrow \mathrm{G} \\
\text { Tarım sektörü; } \varnothing\end{array}$ \\
\hline $\begin{array}{l}\text { Usta ve Berber } \\
\text { (2017) }\end{array}$ & 1970-2012 & Türkiye & $\begin{array}{l}\text { Toda-Yamamoto nedensellik } \\
\text { testi }\end{array}$ & $\begin{array}{l}\text { Ulaştırma ve sanayi sektörü: } \\
E \leftrightarrow G \text {, } \\
\text { Tarım ve konut sektörü: } \varnothing \text {, }\end{array}$ \\
\hline
\end{tabular}

Not: $E \rightarrow G$ enerjiden büyümeye doğru tek yönlü nedenselliği, $G \rightarrow E$ büyümeden enerjiye doğru tek yönlü nedenselliği, $E \leftrightarrow G$ çift yönlü nedenselliği, $\varnothing$ nedensellik ilişkisi olmadığını ifade etmektedir. 


\section{Türkiye'de Ana Sektörlerin Enerji Tüketimi}

Türkiye'nin, üretimde önemli bir girdi olarak kullandığı enerjinin yaklaşık \%70'inde dışa bağımlı olduğu bilinmektedir. Bütün sektörlerde enerji kullanımı 1970'lerden sonra önem verilen başlıca konulardan olmuştur. Dünyada ise 1973 ve 1979 yıllarında yaşanan petrol krizlerinden sonra enerji güvenliğine ve korunmasına karşı önemler alınmıştır. Ulaştırma, ticaret ve tarım gibi sektörlerde enerji kullanımının azaltılmasının yolu enerji tüketiminde etkinliğin artııılmasından geçmektedir (Öztürk ve Bereket, 2005:1).

Enerji tüketimi sanayi sektörü, ulaştırma sektörü, konut ve hizmetler sektörü, tarım sektörü ve enerji dışı sektörlerin tüketim miktarlarının toplamından oluşmaktadır. Enerji dışı olarak adlandııılan sektör, nihai mamul üretimi değil de hammadde üretim sürecinde tüketilen enerji miktarlarını yansıtmaktadır ve toplam enerji tüketimi içerisinde en düşük paya sahip olan sektördür. Bu nedenle çalışmada sektör ayrımı ana sektörlere göre tarım, sanayi ve hizmet olarak yapılacaktır. Ulaştırma sektörünün enerji tüketim rakamları toplanarak, konut ve hizmetler sektörü rakamları içerisinde gösterilmiş, enerji dışı tüketim ise analize dâhil edilmemiştir.

Şekil 1. Türkiye'de Sektörel Enerji Tüketimi Genel Görünümü (BTEP, 1972-2015)

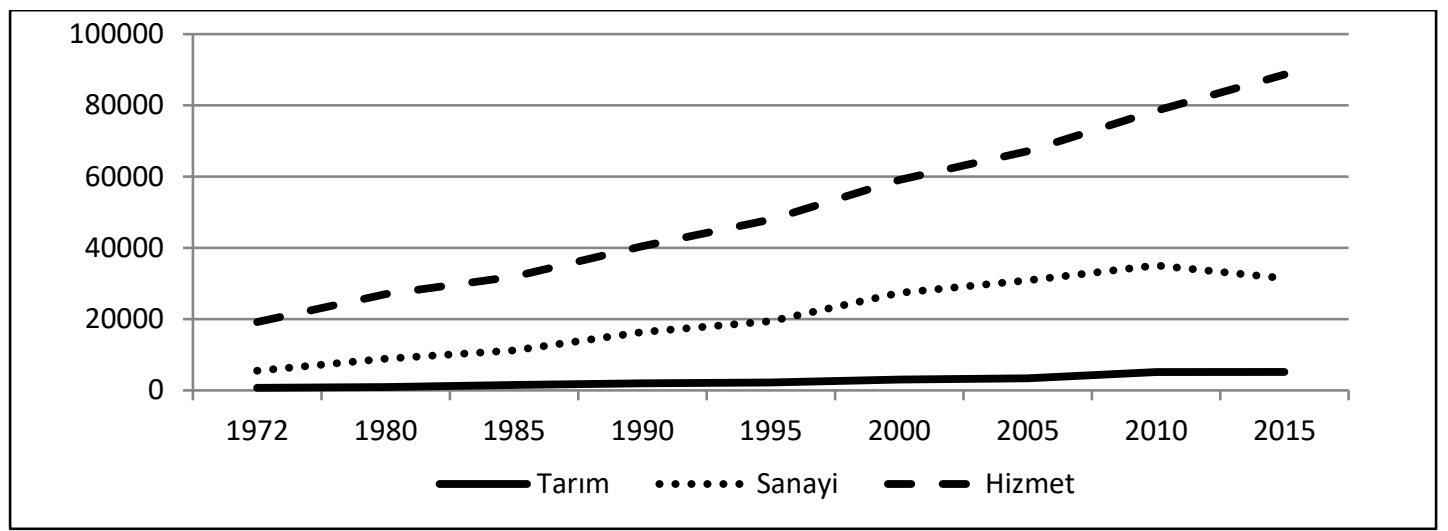

Kaynak: ETKB Enerji Denge Tabloları (1972-2015) kullanılarak hazırlanmıştır (Enerji ve Tabii Kaynaklar Bakanlığı Enerji İşleri Genel Müdürlüğü, 2017).

Şekil 1'de görüldüğü gibi ülkemizin sektörel olarak enerji tüketimi bin ton eşdeğer petrol (BTEP) olarak gösterilmiştir. Tarım teknolojik gelişmelere, iklim şartlarına ve makineleşmeye bağlı olan bir sektördür. 1972'lerde ve sonrasında modern tekniklerin kullanılmaması nedeniyle tarım sektöründe enerji tüketimi sınırlı kalmış ve sektördeki enerji kullanımı günümüzde makineleşmeye ve gelişen teknolojiye bağlı olarak artmaya başlamıştır. Sanayi ve hizmet sektöründe ise üretim artışına bağlı olarak enerji tüketimimiz hala artmaktadır.

2001 krizi sonucu tarım sektöründe azalan üretime bağlı olarak enerji tüketiminin de düştüğü görülmektedir. Diğer yıllarda tekrar büyüme ve ilerleme gösteren tarım sektöründe, özellikle 2007 yılından itibaren enerji tüketimi de artma eğilimine girmiştir.2009 küresel finansal krizi sonrasında Türkiye'de tarım sektörü olumsuz etkilenmiştir. Toplam tüketimdeki daralmaya bağı olarak enerji tüketimi azalma eğilimine girmiştir. İlerleyen birkaç yıl küçük miktarlarda enerji tüketimi artışı görülmüştür.

Sanayi sektöründe ise dalgalı bir seyir gösteren enerji tüketimi 2001 krizine bağlı olarak \%12 küçülmüş, 2005 yılında ise 27.562 BTEP'e yükselmiştir. Ülkemiz 2008 yılında başlayan küresel finansal krizden etkilenmiş, sanayi sektörü \%20 küçülme göstermiştir ve enerji tüketimi 26.266 BTEP’e gerilemiştir. 2009 yılında krizin etkilerinin geçmesiyle birlikte tekrar toparlanmaya başlayan sanayi sektöründe enerji tüketimi tekrar yükselmeye başlamıştır. Hizmet sektöründen farklı olarak sanayi sektöründe enerji tüketiminin payı giderek artmaktadır.

Hizmet sektörü ülkelerin gelişmişlik ve refah seviyesini yükseltmekte olup, önemi hızla artan bir sektördür. Nüfusun ve şehirleşmenin artması gibi nedenlerle konut ve hizmetler sektöründe kullanılan enerji 
türlerinin payı ve özellikle elektrik enerjisinin payı giderek artmaktadır. Hizmetler sektöründeki enerji tüketimi 1973 ve 1979 petrol krizleri hariç 2000'li yıllardan itibaren bazı yıllarda yaşanan düşmelere rağmen sürekli artmıştır. Şekilde görüldüğü üzere, 2010 yılında bu sektörün enerji tüketimi 36.243 BTEP olmuştur ve artış devam etmektedir.

\section{Veri Seti, Metodoloji ve Çıkarımlar}

Bu çalışmada ana sektörlere ait yıllık GSYH ve toplam enerji tüketimi arasındaki ilişki 1972-2015 dönemi için incelenmiştir. Çalışmada ana sektörler bazında enerji tüketimi ve ekonomik büyüme arasındaki ilişkinin analizi için yatay kesit bağımlılığını dikkate alan heterojen panel nedensellik tekniği kullanılmıştır. Bu ilişkinin incelenmesi amacıyla ilk aşamada Pesaran (2004) tarafından geliştirilen "CD (Cross-Sectional Dependence) Testi" kullanılarak sektörler arası yatay kesit bağımlılığı araştırılmıştır. Daha sonra serilerin durağanlık analizi için Im, Pesaran, Shin (2003) tarafından geliştirilen IPS testi ile Pesaran (2007) tarafından geliştirilen CIPS (Cross-sectionally Augmented IPS) testi kullanılmıştır. Son olarak, değişkenler arasındaki nedenselliğin yönünü belirlemek için Dumitrescu ve Hurlin (2012) tarafından geliştirilen heterojen panel nedensellik testi uygulanmıştır.

Çalışmada ekonomik büyüme göstergesi olarak yıllık GSYH kullanılmıştır. GSYH'ye (2010 sabit fiyatlarıyla US\$) ait veriler Dünya Bankası Kalkınma Göstergeleri Veri tabanından-World Development Indicators-WDI, (2017) temin edilmiştir. Ana sektörlere ait toplam enerji tüketim verileri Enerji ve Tabii Kaynaklar Bakanlığı Enerji İşleri Genel Müdürlüğü (EIGM, 2016) Genel Denge Tablolarından elde edilmiştir. Enerji tüketim verileri analize TEP (Ton Eşdeğer Petrol) cinsinden dâhil edilmiştir. Testlerde kullanılan toplam enerji tüketimi ve GSYH değişkenlerinin verileri logaritmik olarak modellenmiştir. Analizde kullanılan değişkenler Tablo 3'te gösterilmiştir.

Tablo 3. Değişkenler Tablosu

\begin{tabular}{|l|l|}
\hline Değişkenler & Ölçüm \\
\hline Enerji Tüketimi & TEP \\
\hline GSYH & 2010 sabit fiyatlarıyla US\$ \\
\hline $\log _{\mathrm{e}}$ & Enerji Tüketimi \\
\hline $\log _{\mathrm{y}}$ & GSYH \\
\hline
\end{tabular}

\subsection{Yatay Kesit Bağımlılığı Testi}

Bu çalışmada sektörler arasındaki bağımlılığın tespiti için Pesaran (2004) tarafından geliştirilen ve (1) numaralı denklemle ifade edilen CD Testi kullanılmışır. Genellikle panel veri modellerinde birimlerin bağımsız oldukları varsayılmaktadır. Ancak son çalışmalarda birimler arasında herhangi bir bağımlılık olup olmadığı incelenmektedir. $T$ zaman aralığı, $N$ birimler ve $p_{i j}$ ise çift katlı korelasyonun örnek tahminini gösteren Pesaran (2004) "CD Testi" modeli aşağıdaki gibidir.

$$
C D=\sqrt{\frac{2 T}{N(N-1}}\left(\sum_{i=1}^{N-1} \sum_{j=i+1}^{N} \widehat{p_{l j}}\right)
$$

CD test, Breusch-Pegan (1980) tarafından geliştirilen Lagrange Multiplier (LM) testinin genişletilmiş halidir. Breusch-Pegan (1980) tarafından geliştirilen LM testinde panelin zaman boyutu yatay kesit boyutundan büyük olduğunda yatay kesitin varlığını incelemektedir. CD testinde ise zaman boyutu yatay kesit boyutundan büyük ve yatay kesit boyutu zaman boyutundan büyük olduğu zaman kullanılmaktadır. 
Tablo 4. Pesaran (2004) Yatay Kesit Bağımlılı̆ı Test Sonuçları

\begin{tabular}{|c|c|c|}
\hline Değişken & CD Test & P-Value \\
\hline $\log _{\mathrm{e}}$ & 10,16 & 0,00 \\
\hline $\log _{\mathrm{y}}$ & 11,49 & 0,00 \\
\hline
\end{tabular}

Not: P-Value olasılık değerini ifade etmektedir. Analiz STATA programı kullanılarak yapılmıştır.

Tablo 4'te Pesaran (2004) CD Testine göre $\boldsymbol{H}_{0}$ : Yatay kesit bağımlılı̆ı yoktur şeklinde kurulan boş hipotez $\boldsymbol{H}_{A}$ : Yatay kesit bağımlıığı vardır şeklinde kurulan alternatif hipoteze karşı sınanmıştır. Analizden elde edilen sonuca göre boş hipotez $\left(\boldsymbol{H}_{0}\right)$ reddedilmiş olup, bu durum paneli oluşturan birimler arasında ilişki olduğunu göstermektedir.

\subsection{Birim Kök Testi}

Günümüzde panel veriler için birçok birim kök testleri geliştirilmiştir. Panel birim kök testleri “I. Nesil Testler" ve "II. Nesil Testler" olarak ayrılmaktadır. I. Nesil Testler, yatay kesitler arasında bağımlılığın olmadığını varsaymaktadırlar. Bunlardan en sık kullanılanları Levin, Lin ve Chu (LLC, 2002) ve Im, Pesaran ve Shin (IPS, 2003) testleridir. II. Nesil Testlerden sıklıkla kullanılanları ise Pesaran (CIPS, 2007), Pesaran Crosssectionally Augmented Dickey Fuller (CADF, 2007) testleridir. Bu testler yatay kesit bağımlılığını göz önüne alarak geliştirilmiştir.

Im, Pesaran ve Shin (IPS, 2003), paneldeki tüm birimlerin homojen bir katsayıya sahip olduğunu kabul eden Levin, Lin ve Chu (LLC, 2002) test istatistiğinden hareketle paneldeki tüm birimlerin heterojen katsayılı olabileceğini varsayarak yeni bir test istatistiği geliştirmişlerdir. LLC testinde olduğu gibi, IPS testinde de "seri birim kök içermez" biçiminde kurulan alternatif hipotezi, "seri birim kök içerir" biçiminde kurulan boş hipoteze karşı sınanmaktadır.

Çalışmada enerji tüketimi için kullandığımız verilerimiz için yatay kesit bağımlılığı olduğu sonucu elde edilmiştir. Bu nedenle $\log _{e}$ için II. Nesil Testlerden olan ve (2) numaralı denklemle gösterilen Pesaran (2007) CIPS testi kullanılmıştır. CIPS testi Im, Pesaran ve Shin tarafından geliştirilen IPS testinin geliştirilmiş halidir. Aşağıda CIPS testi modelinde gösterilen $t_{i}(N, T)$ ise Dickey Fuller (CADF) istatistiğinden eklenmiştir.

$$
\operatorname{CIPS}(N, T)=N^{-1} \sum_{i=1}^{N} t_{i}(N, T)
$$

$\log _{y}$ serisinin durağanlığı ise I. Nesil testlerden IPS testi kullanılarak sınanmıştır. Gelir değişkeni sektörlere göre değişken değildir. Bu nedenle yatay kesit sonuç da veren IPS testi kullanmak daha doğru sonuç üretecektir.

Tablo 5. Panel Birim Kök Test Sonuçları

\begin{tabular}{|l|c|c|c|c|}
\hline \multicolumn{1}{|c|}{ Panel } & Değişken & Test & Test İstatistiği & P-Value \\
\hline Havuzlanmış & $\log _{\mathrm{e}}$ & CIPS & $-1,725$ & $0,04^{* *}$ \\
\hline Havuzlanmış & $\log _{\mathrm{y}}$ & IPS & $-2,34$ & $0,00^{*}$ \\
\hline Tarım & $\log _{\mathrm{y} 1}$ & IPS & $-3,26$ & $0,08^{* * *}$ \\
\hline Sanayi & $\log _{\mathrm{y} 2}$ & IPS & $-3,26$ & $0,08^{* * *}$ \\
\hline Hizmet & $\log _{\mathrm{y} 3}$ & IPS & $-3,26$ & $0,08^{* * *}$ \\
\hline
\end{tabular}

Not: Bu testte gecikme sayısı 1 alınmıştır ve analiz için sabit ve trendli model kullanılmıştır. *, **, *** sırasıyla \%1, \%5 ve \%10 anlamlılık seviyesini ifade etmektedir. Analiz Stata programı kullanılarak yapılmıştır. 
CIPS ve IPS testlerine göre değişkenlerin değerleri için "Birim kök içermez, durağandır" şeklinde kurulan alternatif hipotez $\left(\boldsymbol{H}_{\boldsymbol{A}}\right)$, "Birim kök içerir. Durağan değildir" şeklinde kurulan boş hipoteze $\left(\boldsymbol{H}_{\boldsymbol{0}}\right)$ karşı sınanmıştır. Analizden elde edilen sonuca göre "Birim kök içerir, durağan değildir" şeklinde kurulan boş hipotez $\left(\boldsymbol{H}_{0}\right)$ reddedilebilir. Buna göre panel birim kök test sonuçlarından serilerin $\% 1, \% 5$ ve $\% 10$ anlamlılık düzeyine göre durağan oldukları sonucuna varılmıştır. Sonuçlar Tablo 5'te görülmektedir.

\subsection{Nedensellik Testi}

Değişkenler arasındaki ilişkinin yönünün belirlenmesinde en fazla kullanılan yöntemler arasında Granger (1969) tarafından geliştirilen nedensellik testi yer almaktadır. Ancak bu çalışmada değişkenler arasındaki nedensellik ilişkisini incelemek için Dumitrescu ve Hurlin (2012) tarafından geliştirilen heterojen panel nedensellik testi kullanılmıştır. Bu testin avantajı, yatay kesit bağımlılı̆ını göz önüne alınması ve değişkeler arasındaki heterojenliğe dikkat etmesidir. Dumitrescu ve Hurlin yaklaşımının diğer bir avantajı da zaman boyutunun yatay kesit boyutundan büyük ya da küçük olduğu durumlarda da kullanılabilmesi ve dengesiz veri setlerinde de etkin sonuçlar vermesidir.

(3) numaralı denklemle ifade edilen nedensellik analizinde durağan $\mathrm{x}$ ve y değişkenleri, $T$ dönem boyunca $N$ sayıda birim için aşağıdaki gibi doğrusal heterojen model ile tanımlanmaktadır (Dumitrescu ve Hurlin, 2012: 5):

$$
y_{i, t}=a_{i}+\sum_{k=1}^{K} \gamma_{\mathrm{i}}^{(k)} y_{i, t-k}+\sum_{k=1}^{K} \beta_{\mathrm{i}}^{(k)} x_{i, t-k}+\varepsilon_{i, t}
$$

Modelde $\beta_{i}=\left(\beta_{i}^{(1)}, \beta_{i}^{(2)}, \beta_{i}^{(3)} \cdots \beta_{i}^{(K)}\right)$ şeklindedir. Bireysel etkilerin $\alpha_{i}$ sabit olduğu, gecikme parametreleri $\gamma_{i}^{(k)}$ ve regresyon eğim katsayıları $\beta_{i}^{(k)}$ 'nın birimler arasında değiştiği ve burada yer alan gecikme sayısı $K$ 'nın yatay kesitlerde aynı olduğu varsayılmaktadır. Dolayısıyla yapılan nedensellik testi için sabit etkiler modeli kurulmaktadır. Denklemden faydalanılarak oluşturulan boş ve alternatif hipotezler şöyledir (Dumitrescu ve Hurlin, 2012:6)

$$
\begin{array}{lcc}
H_{0}: \beta_{1}=0 & \forall i=1, \cdots N & \\
H_{A}: \beta_{1}=0 & \forall i=1, \cdots N_{1} & 0 \leq N_{1} / N<1 \\
\beta_{1} \neq 0 & \forall i=N_{1}+1, N_{1}+2, \cdots N &
\end{array}
$$

Boş hipoteze $\left(\boldsymbol{H}_{\mathbf{0}}\right)$ göre tüm birimlerin incelenen değişkenleri arasında herhangi bir nedensellik ilişkisi yoktur. Alternatif hipotez $\left(\boldsymbol{H}_{\boldsymbol{A}}\right)$ ise en az bir birimde iki değişken arasında nedensellik olduğunu ifade etmektedir. Kullanılan modelin heterojen olmasına rağmen temel hipotez homojen bir sonuca, alternatif hipotez ise heterojen bir sonuca ulaşmayı sağlamaktadır.

Tablo 6'da Dumitrescu ve Hurlin heterojen panel nedensellik testine göre büyümeden enerji tüketimine doğru hiçbir sektörde nedensellik yoktur şeklinde kurulan boş hipotezimiz $\left(\boldsymbol{H}_{0}\right)$, büyümeden enerji tüketimine doğru en az bir sektörde nedensellik vardır şeklinde kurulan alternatif hipoteze $\left(\boldsymbol{H}_{\boldsymbol{A}}\right)$ karşı sınanmıştır.

Dumitrescu ve Hurlin testinden elde edilen sonuçlara göre;

- Tarımda 2. gecikme sayısından itibaren büyümeden enerji tüketimine tek yönlü,

- Hizmetler sektöründe 2. gecikme sayısından itibaren büyümeden enerji tüketimine ve enerji tüketiminden büyümeye doğru çift yönlü bir nedensellik ilişkisi bulunmuştur.

- Sanayi sektöründe ise herhangi bir nedensellik ilişkisi bulunamamıştır. 
Ana Sektörlerin Enerji Tüketimlerinin Ekonomik Büyüme Üzerine Etkisi: Türkiye Örneği (1972-2015)

Tablo 6. Dumitrescu ve Hurlin (2012) Heterojen Panel Nedensellik Testi Sonuçları

\begin{tabular}{|c|c|c|c|}
\hline Gecikme Sayısı & Sektör & $\mathbf{G} \rightarrow \mathbf{E}$ & $\mathbf{E} \rightarrow \mathbf{G}$ \\
\hline \multirow{3}{*}{ K=1 } & Havuzlanmış Panel & $7,418(0,00)$ & $-1,113(0,26)$ \\
\cline { 2 - 4 } & Tarım & $1,472(0,225)$ & $0,054(0,89)$ \\
\cline { 2 - 4 } & Sanayi & $0,0003(0,985)$ & $0,146(0,70)$ \\
\cline { 2 - 4 } & Hizmet & $19,699(0,00)$ & $0,072(0,78)$ \\
\hline \multirow{3}{*}{ K=2 } & Havuzlanmış Panel & $8,377(0,000)$ & $1,618(0,10)$ \\
\cline { 2 - 4 } & Tarım & $5,864(0,05)$ & $1,738(0,41)$ \\
\cline { 2 - 4 } & Sanayi & $1,662(0,435)$ & $1,483(0,47)$ \\
\cline { 2 - 4 } & Hizmet & $12,982(0,001)$ & $5,580(0,06)$ \\
\hline \multirow{3}{*}{ K=3 } & Havuzlanmış Panel & $2,342(0,01)$ & $1,185(0,23)$ \\
\cline { 2 - 4 } & Tarım & $9,982(0,01)$ & $2,033(0,56)$ \\
\cline { 2 - 4 } & Sanayi & $1,430(0,693)$ & $0,921(0,82)$ \\
\cline { 2 - 4 } & Hizmet & $9,377(0,024)$ & $7,722(0,09)$ \\
\hline
\end{tabular}

Not: Parantez içindeki değerler olasılık değerlerini ( $p$-value) göstermektedir. G büyümenin, E ise enerji tüketimin kısaltması olarak kullanılmıştır. $\mathrm{K}$ ise gecikme sayısını göstermektedir. Analiz MATLAB programı kullanılarak yapılmıştır.

\subsection{Bulguların Değerlendirilmesi ve Çıkarımlar}

Çalışmada ilk önce yatay kesit bağımlılığı testi ile sektörler arasında bağımlılık olup olmadığı Pesaran (2004) CD Testiyle test edilmiştir. Enerji tüketimi ve GSYH göstergesi olarak logaritmik değerler (sırasıyla $\log _{e}$ ve $\log _{y}$ ) kullanılmış olasılık değerlerinin $\% 1, \% 5$ ve $\% 10^{\prime}$ da anlamlı olduğu bulunmuştur. $H_{0}$ Hipotezi reddedilmiştir. Kısaca sektörlerde enerji tüketimi $\left(\log _{e}\right)$ ve GSYH $\left(\log _{y}\right)$ arasında bağımlılık olduğu sonucuna ulaşılmıştır.

Panel birim kök testinde değişkenlerin gecikme sayısı 1 alınarak sabit ve trendli model kullanılmıştır. Değişkenlere ait olasılık değerlerinin \%10 anlamlılık düzeyinde durağan olduğu tespit edilmiştir. Modelde serilerin birim kök içerdiğini varsayan $H_{0}$ hipotezi reddedilerek analizin birim kök içermediği sonucuna ulaşılmıştır.

Nedensellik testi için yapılan Dumitrescu ve Hurlin (2012) heterojen panel nedensellik analizine göre olasılık değerlerimiz \%10 anlamlılık düzeyinde, 3 gecikme sayısı ile birlikte $G \rightarrow E$ ve $E \rightarrow G$ şeklinde ele alınmıştır.

Yapılan analiz sonucunda tarım sektöründe 2. gecikmeden itibaren $(G \rightarrow E)$ ilişkisi için tek yönlü nedensellik bulunmuştur. Yani koruma hipotezinin geçerlidir. Bu durumda enerji tüketimini azaltmanın ekonomik büyüme üzerinde negatif bir etkisi bulunmamaktadır.

Hizmet sektöründe 2. gecikmeden itibaren çift yönlü $(G \leftrightarrow E)$ nedensellik bulunmuştur. Geri besleme hipotezi de denilen bu nedensellik sonucuna göre, enerji tüketimi ve ekonomik büyüme karşılıklı olarak bir ilişki içerisindedirler. Enerji tüketiminde yaşanan artışlar ekonomik büyümeyi artırmaktadır. Böylece büyüyen ekonomide tekrar enerji kullanımı teşvik edilmektedir.

Sanayi sektöründe $E \rightarrow G^{\prime}$ ye herhangi bir nedensellik ilişkisi bulunamamıştır. Nedenselliğin olmadığı bu tarafsızlık hipotezine göre büyüme üzerinde enerjinin rolü sıfır ya da minimum olarak tanımlanmıştır. Büyümeden enerji tüketimine doğru ise tek yönlü bir nedensellik ilişkisi olduğu tespit edilmiştir.

Boş hipoteze $\left(\boldsymbol{H}_{0}\right)$ göre büyümeden enerji tüketimine doğru hiçbir sektörde nedensellik yoktur. Alternatif hipoteze $\left(\boldsymbol{H}_{\boldsymbol{A}}\right)$ göre ise büyümeden enerji tüketimine doğru en az bir sektörde nedensellik söz 
konusudur. Elde edilen sonuçlara göre büyümeden enerji tüketimine doğru 1 gecikme sayısı ele alındığında, havuzlanmış panel analizi çerçevesinde nedensellik olduğu sonucuna ulaşılış̧tır. Yani 1 yıl gecikmede en az bir sektörde nedensellik vardır ( $\boldsymbol{H}_{0}$ reddedilir, $\boldsymbol{H}_{\boldsymbol{A}}$ kabul edilir). Hizmet sektöründe büyümeden enerji tüketimine doğru büyüme vardır. Yani ulaşılan sonuca göre ekonomik büyüme enerji tüketimine yol açmıştır. 2 ve 3 yıl gecikme sayısında tarım ve hizmet sektöründe büyümeden enerji tüketimine doğru nedensellik ilişkisi bulunmuştur. Sanayi sektörü için büyümeden enerji tüketimine doğru herhangi bir nedensellik ilişkisi bulunamamıştır.

Enerji tüketiminden büyümeye doğru nedensellik ilişkisi incelendiğinde havuzlanmış panel verilerinde enerji tüketiminden büyümeye doğru bir nedensellik bulunamamıştır. Yani enerji tüketimi gecikme uzunluklarında büyümeye etki etmemektedir. Ekonomik büyüme olsa bile enerji tüketiminden kaynaklanmamıştır. Yalnızca 2 ve 3 yıl gecikmede hizmetler sektöründe enerji tüketiminden büyümeye doğru nedensellik bulunmuştur. Büyüme hipotezi de denilen bu nedensellik sonucuna göre enerji tüketiminde yaşanan artışlar reel büyümenin artmasına, aynı zamanda enerji tüketimini azaltmak için uygulanacak politikalarında büyüme üzerinde negatif bir etki bırakmasına sebep olmaktadır. Bir ekonomide bu hipotezin geçerli olması ekonominin ana sektörler itibariyle enerjiye bağımlı olduğunu göstermektedir.

\section{Sonuç}

Günümüzde enerji tüketimi, ülkelerin ekonomik büyüme ve kalkınma düzeyini gösteren önemli göstergeler arasındadır. Enerji kaynaklarının ülkelere göre farklılık göstermesi, artan nüfus, hızla gelişen teknoloji, sanayileşmenin artması gibi nedenlerle enerji tüketimin artması ve elde bulunan rezervlerin gelecek kuşaklara aktarılabilmesi için yapılan politika önerileri kapsamında, enerji olgusu ülkelerin temel ekonomik konuları arasındadır. Türkiye ekonomisinde üretim faktörleri sanayi ve hizmet sektörüne kaydıkça sektörlerdeki üretim artışına paralel olarak enerji tüketimi de artmıştır. Tarım sektöründe ise gelişen teknolojiyle birlikte modern tarım teknikleri kullanımı artmış ve bu durum beraberinde enerji tüketim artışını getirmiştir. Bu nedenlerle enerji tüketiminin etkin ve verimli bir şekilde yapılarak, ekonomik büyüme üzerindeki etkilerinin araştırılması önemlidir.

Çalışmada kullanılan Dumitrescu ve Hurlin (2012) tarafından geliştirilmiş heterojen panel nedensellik analizine göre Türkiye'de büyümeden enerji tüketimine doğru tek yönlü bir nedensellik ilişkisi bulunmuştur. Tarım sektöründe büyümeden enerji tüketimine doğru tek yönlü, hizmetler sektöründe ise büyüme ve enerji tüketimi arasında çift yönlü nedensellik ilişkisi bulunmuştur. Sanayi sektöründe ise herhangi bir nedensellik bağı bulunamamıştır. Bu çalışma daha önce Türkiye için yapılan Jobert ve Karanfil (2007)'in çalışmasını desteklemektedir. Buna göre enerji tüketimi ekonomik büyümeyi etkilemeyecektir. Ancak söz konusu çalışma sadece havuzlanmış veriler dikkate alınarak yapılmış olup hem havuzlanmış veri kullanması hem de sektörler bazında inceleme yapması yönüyle Jobert ve Karanfil (2007)'in çalışmasından ayrılmaktadır. İlaveten Şahbaz ve Yanar'ın (2013) 1970-2010 dönemlerinde Türkiye için yaptıkları çalışmalarını sanayide nedenselliğin olmaması, büyümeden enerji tüketimine doğru tek yönlü ve tarım sektöründe büyümeden enerji tüketimine tek yönlü nedensellik bulgularının aynı olması nedeniyle desteklemektedir. şunlardır.

Politika açısından enerji-büyüme ilişkisi çerçevesinde dikkat edilmesi gereken başlıca konular

- Enerji sektöründe, birincil enerji kaynaklarının kullanımında dışa bağımlıık azaltılmalı, yenilenebilir ve temiz enerji kaynakları değerlendirilmelidir.

- Enerji politikalarında toplumsal fayda düşünülerek ucuz, sürekli ve güvenilir, kolay erişilebilecek ve çevreye zararı en az olan enerji kaynaklarının bulunması hedeflenmelidir.

- Gelişmekte olan ülkeler arasında olan Türkiye'nin enerji ihtiyacı giderek artmaktadır. Bu nedenle mevcut kaynaklarını verimli kullanmalıdır. Yenilenebilir enerji kaynakları bakımından zengin olan ülkemiz yeni enerji politikalarında bu kaynakları değerlendirmelidir.

- Kısacası Türkiye'de enerji kullanımı sürdürülebilir hale getirilmeli, böylece kalkınmanın sürdürülebilirliği temin edilmelidir. 
- Konuyla ilgili yeni yapılacak olan araştırmalar açısından ise şu öneriler getirilebilir.

- Bu çalışmada, literatüre uygun olarak, Türkiye'de ana sektörlerin enerji tüketimlerinin büyüme üzerine etkisi üç gecikme sayısına göre incelenmiş, sanayi sektöründe herhangi bir nedensellik ilişkisine rastlanamamıştır. Sanayi sektöründe ortaya çıkan bu sonuç dört gecikme sayısı olduğu zaman değişebilecek mi sorusu, başka çalışmalar için konu oluşturabilir. Yani analizlerde alınan gecikme sayısı artırılabilir.

- Literatürdeki çalışmaların çok büyük bir kısmında sektör ayrımı yapılmamıştır. Bu çalışmada Türkiye'de ana sektörler (tarım, sanayi ve hizmet) ayrımı yapılarak enerji tüketimi ve ekonomik büyüme arasındaki ilişki incelenmiştir. Bundan sonraki çalışmalarda da sektör ayrımı yapılarak, daha doğru politikaların tespit edilebilmesine yardımcı olunmalıdır.

- Yapılacak olan diğer çalışmalarda ana sektörlerin daha alt sektörlerine inilebilir ve analiz derinleştirilebilir.

\section{Kaynaklar}

Abbas, F., \& Choudhury, N. (2013). Electricity consumption-economic growth nexus: An aggregated and disaggregated causality analysis in India and Pakistan. Journal of Policy Modelling, 538-553.

Al-Mulali, U., Fereidouni, H. G., Lee, J. Y., \& Sab, C. N. B. C. (2013). Examining the bi-directional long run relationship between renewable energy consumption and GDP growth. Renewable and Sustainable Energy Reviews, 22, 209222.

Altınay, G., \& Karagöl, E. (2004). Structural break, unit root, and the causality between energy consumption and GDP in Turkey. Energy Economics, 26(6), 985-994.

Apergis, N., \& Payne, J. E. (2009). Energy consumption and economic growth: Evidence from the Commonwealth of Independent States. Energy Economics, 31, 641-647.

Apergis, N., \& Payne, J. E. (2012). Renewable and non-renewable energy consumption-growth nexus: Evidence from a panel error correction model. Energy Economics, 34(2), 733-738.

Aslan, A., \& Öcal, O. (2016). The role of renewable energy consumption in economic growth: Evidence from asymmetric causality. Renewable and Sustainable Energy Reviews, 60, 953-959.

Bakırtaş, T., \& Akpolat, A. G. (2018). The relationship between energy consumption, urbanization and economic growth in new emerging-market countries. Energy, 147, 110-121.

Belloumi, M. (2009). Energy consumption and GDP in Tunisia: Cointegration and causality analysis. Energy Policy, 37, 2745-2753.

Bildirici, M., \& Ersin, Ö. (2015). An investigation of the relationship between the biomass energy consumption, economic growth and oil prices. Social and Behavioural Sciences, 210(2), 203-212.

Bowden, N., \& Payne, J. E. (2009). The causal relationship between U.S. energy consumption and real output: A disaggregated analysis. Journal of Policy Modelling, 31(2), 180-188.

Chen, S. T., Kuo, H. I., \& Chen, C. C. (2007). The relationship between GDP and electricity consumption in 10 Asian countries. Energy Policy, 35(4), 2611-2621.

Çetin, M., \& Şeker, F. (2012). Enerji tüketiminin ekonomik büyüme üzerine etkisi: Türkiye örneği. Uludağ Üniversitesi iiBF Dergisi, 30(1),85-106.

Destek, M. A., \& Aslan, A. (2017). Renewable and non-renewable energy consumption and economic growth in emerging economies: Evidence from bootstrap panel causality. Renewable Energy, 111, 757-763.

Dumitrescu E., \& Hurlin, C. (2012). Testing for granger non-causality in heterogeneous panel. Economic Modelling, 29(4), 1450-1460.

Dünya Bankası (2017). Dünya Kalkınma Göstergeleri Veri Tabanı, https://data.worldbank.org/data-catalog/worlddevelopment-indicators, (Erişim Tarihi, 07.01.2017).

Enerji ve Tabii Kaynaklar Bakanlığı (2017). Enerji Denge Tabloları. http://www.eigm.gov.tr/tr, (Erişim Tarihi, 14.08.2017). 
Gross, C. (2012). Explaining the non-causality between energy and economic growth in the USA multivariate sectoral analysis. Energy Economics, 489-499.

Hamit-Haggar, M. (2012). Greenhouse gas emissions, energy consumption and economic growth: A panel cointegration analysis from Canadian industrial sector perspective. Energy Economics, 34(1), 358-364.

Hammami, S., \& Saidi, K. (2015). Energy consumption and economic growth nexus: Empirical evidence from Tunisia. International Journal of Information, Business and Management, 7(1), 269-370.

Im, K. S., Pesaran, M. H., \& Shin Y. (2003). Testing for unit roots in heterogeneous panels. Journal of Econometrics, 115(1), 53-74.

Ito, K. (2017). Co2 emissions, renewable and non-renewable energy consumption and economic growth: evidence from panel data for developing countries. International Economics, 151, 1-6.

Jamil, F., \& Ahmad, E. (2010). The relationship between electricity consumption, electricity prices and GDP in Pakistan. Energy Policy, 38(10), 6016-6025.

Jobert, T., \& Karanfil, F. (2007). Sectoral energy consumption by source and economic growth in Turkey. Energy Policy, 35(11), 5447-5456.

Jumbe, C. B. L. (2004). Cointegration and causality between electricity consumption and GDP: Empirical evidence from Malawi. Energy Economics, 26(1), 61-68.

Korkmaz, Ö., \& Develi, A. (2012). Türkiye'de birincil enerji kullanımı, üretimi ve gayri safi yurt içi hâsıla (GSYH) arasındaki ilişki. Dokuz Eylül Üniversitesi Iktisadi ve Idari Bilimler Fakültesi Dergisi, 27(2), 1-25.

Kraft, J., \& Kraft, A. (1978). On the relationship between energy and GNP. Journal of Energy Development, 3, $401-403$.

Lee, C. C. (2005). Energy consumption and GDP in developing countries: A cointegrated panel analysis. Energy Economics, 415-427.

Mucuk, M., \& Uysal, D: (2009). Türkiye ekonomisinde enerji tüketimi ve ekonomik büyüme. Maliye Dergisi, 157, 105115.

Mutascu, M. (2016). A bootstrap panel granger causality analysis of energy consumption and economic growth in the G7 countries. Renewable and Sustainable Energy Reviews, 63, 166-171.

Narayan, P. K., \& Smyth, R. (2008). Energy consumption and real GDP in G7 countries: New evidence from panel cointegration with structural breaks. Energy Economics, 30(5), 2331-2341.

Öztürk, H. H., \& Bereket, B.Z. (2005). Türkiye tarımında enerji kullanımı, Türkiye Ziraat Mühendisliği Vı. Teknik Kongresi, Ankara, 1253-1264.

Öztürk, i. (2010). A Literature survey on energy-growth nexus. Energy Policy, 38(1), 340-349.

Pesaran, M. H. (2007). A simple panel unit root test in the presence of cross-section dependence. Journal of Applied Econometrics, 22(2), 265-312.

Pesaran, M. H. (2004). General Diagnostic Tests for cross section dependence in panels. Cambridge Working Papers in Economics, 1229.

Saunorıs, J. W., \& Sheridan, B. J. (2013). The dynamics of sectoral electricity demand for a panel of us states: New evidence on the consumption-growth nexus. Energy Policy, 61, 327-336.

Sebri, M., \& Abid, M. (2012). Energy use for economic growth: A trivariate analysis from Tunisian agriculture sector. Energy Policy, 48, 711-716.

Shahbaz, M., Tang, C. F., \& Shabbir, S. M. (2011). Electricity consumption and economic growth nexus in Portugal using cointegration and causality approaches. Energy Policy, 3529-3536.

Shuyun, Y. A., \& Donghu, Y. (2011). The causality between energy consumption and economic growth in China: Using panel method in a multivariate framework. Energy Procedia, 5, 808-812.

Şahbaz, A., \& Yanar, R. (2013). Türkiye'de toplam ve sektörel enerji tüketimi ile ekonomik büyüme ilişkisinin ekonometrik analizi. Finans Politik \& Ekonomik Yorumlar, 50(575), 31-44.

Tang, C. F., \& Shahbaz, M. (2013). Sectoral analysis of the causal relationship between electricity consumption and real output in Pakistan. Energy Policy, 60, 885-891.

Tsani, T. S. (2010). Energy consumption and economic growth: A causality analysis for Greece. Energy Economics, $582-$ 590.

Tuğcu, C. T., \& Topcu, M. (2018). Total, renewable and non-renewable energy consumption and economic growth: Revisiting the issue with an asymmetric point of view. Energy, 152, 64-74. 
Uçan, O., Arıcıoğlu, E. \& Yücel, F. (2014). Energy consumption and economic growth nexus: Evidence from developed countries in Europe. International Journal of Energy Economics and Policy, 4(3), 411-419.

Usta, C., \& Berber, M. (2017). Türkiye'de enerji tüketimi ekonomik büyüme ilişkisinin sektörel analizi. Ekonomik ve Sosyal Araştırmalar Dergisi, 13(1), 173-187.

Wolde-Rufael, Y. (2004). Disaggregated industrial energy consumption and GDP: The case of Shanghai, $1952-1999$. Energy Economics, 26(1), 69-75.

Yu, E. S. H., \& Hwang, B. K. (1984). The relationship between energy and GNP: Further results. Energy Economics, 6, 186-90.

Yu, E. S. H., \& Choi, Y. J. (1985). The causal relationship between energy and GNP: An international comparison. Journal of Energy Finance \& Development, 10(2), 249-272.

Zhang, C., \& Xu, J. (2012). Retesting the causality between energy consumption and GDP in China: Evidence from sectoral and regional analyses using dynamic panel data. Energy Economics, 34(6), 1782-1789. 